\title{
Possible nonopioid-mediated analgesia produced by methotrimeprazine in rats
}

\author{
Perry N Fuchs PhD, Bradley Kerr, Ronald Melzack PhD
}

M ethotrimeprazine (MTMZ) is a phenothiazine derivative related to chlorpromazine. Several earlier reports have indicated that MTMZ has analgesic properties and produces

PN Fuchs, B Kerr, R Melzack.

Possible nonopioid-mediated analgesia produced by methotrimeprazine in rats.

Pain Res Manage 1996;1(4):207-211.

BACKGROUND: Several reports in the 1960s demonstrated that methotrimeprazine (MTMZ), a phenothiazine derivative, is effective for treating acute and chronic pain. Although MTMZ has received little attention in recent decades, the fact that it derives from a class of drugs usually associated with cognitive and emotional processes, rather than the traditional analgesics, makes it interesting as a potential source of information about the mechanisms of analgesia.

OBJECTIVE: To explore the analgesic properties of MTMZ in a dose-related design in the formalin test, and to examine whether the lowest dose of MTMZ that produces analgesia will activate endogenous opioid systems. compared with a saline control, were explored in male SpragueDawley rats using the formalin test. Sedative effects were studied by using the line-crossing test concomitantly with the formalin test.

RESULTS: MTMZ had no effect during the first phase of formalin responding. During the second phase of the formalin test, MTMZ doses of 5.0 and $10.0 \mathrm{mg} / \mathrm{kg}$ produced a significant decrease in formalin responses. Sedative effects were observed at all doses, even though the dose of $2.5 \mathrm{mg} / \mathrm{kg}$ did not significantly decrease formalin responses compared with controls. Statistical analyses revealed no significant correlation between the degree of sedation and the degree of analgesia at any dose of MTMZ. The nonspecific opioid antagonist naloxone did not alter the analgesic effect of $5.0 \mathrm{mg} / \mathrm{kg} \mathrm{MTMZ}$, indicating that the mechanism of action is independent of endogenous opioid systems.

CONCLUSION: MTMZ decreased responses in the formalin pain test in rats. Although the drug's sedative effects were apparent in the line crossing test, they were not significantly correlated with
METHODS: The analgesic properties of three doses of MTMZ,

dose-related analgesia that is comparable with that of opioid analgesics (1-6). MTMZ has been reported to be effective for the treatment of various types of clinical pain, such as herpes zoster pain (1), can-

pain responses. These results suggest that the decrease in formalin responses might be due, in part at least, to the analgesic properties of MTMZ. The fact that MTMZ belongs to a class of drugs that is relatively unexplored in relation to pain and analgesia indicates a potential source for the development of new pharmacological agents for treating persistent pain. Furthermore, the nonopioid mechanism of action suggests that this agent may be useful when opioid medications are contraindicated.

Key Words: Analgesia, Formalin test, Methotrimeprazine, Neuroleptic, Nozinan, Pain

\section{Éventuelle analgésie à médiation non opioïde produite par la méthotriméprazine chez le rat}

HISTORIQUE : Dans les années 60, plusieurs rapports ont démontré que la méthotriméprazine (MTMZ), un dérivé de la phénothiazine, est efficace dans le traitement de la douleur aiguë et chronique. Bien que la MTMZ ait reçu peu d'attention ces dernières décennies, le fait qu'elle soit dérivée d'une classe de médicaments qui habituellement sont associés à des processus cognitifs et émotionnels, plutôt que des analgésiques classiques, la rend intéressante comme source d'information sur les mécanismes de l'analgésie.

OBJECTIF : Explorer les propriétés analgésiques de la MTMZ dans un modèle lié à la dose dans le test au formol, et examiner si la dose la plus faible de MTMZ qui produit l'analgésie activera les systèmes opioïdes endogènes.

MÉTHODES : Les propriétés analgésiques de trois doses de MTMZ comparées à un témoin salin, ont été explorées chez des rats mâles Sprague-Dawley en utilisant le test au formol. Les effets sédatifs ont été étudiés en utilisant le test de dépassement de la ligne simultanément avec le test au formol.

RÉSULTATS : La MTMZn'a aucun effet pendant la première phase de la réponse au formol. Pendant la deuxième phase du test au formol, des doses de MTMZ de 5,0 et 10,0 mg/kg ont entraîné une chute significative de la réponse au formol. Les effets sédatifs ont été observés à toutes les doses, bien que la dose de $2,5 \mathrm{mg} / \mathrm{kg}$ n'ait pas diminué la réponse au formol de

voir page suivante

McGill University, Department of Psychology, Montreal, Quebec

Correspondence: Dr Perry N Fuchs, Johns Hopkins School of Medicine, Department of Neurosurgery, Room 5-109, Meyer Building, 600 North

Wolfe Street, Baltimore, MD 21287, USA. Telephone 410-955-2250, fax 410-955-1032, e-mail fuchs@welchlink.welch.jhu.edu

Accepted for publication October 1, 1996 
degré d'analgésie quel que soit la dose de MTMZ. Le naloxone, antagoniste opioïde non spécifique, n'a pas modifié l'effet analgésique produit par une dose de MTMZ de $5,0 \mathrm{mg} / \mathrm{kg}$, ce qui indique que le mécanisme d'action est indépendant des systèmes opioïdes endogènes.

CONCLUSIONS : La MTMZ a diminué la réponse lors du test au formol chez le rat. Bien que le test de dépassement de la ligne ait mis en évidence les effets sédatifs de ce médicament, aucune corrélation significative n'a pu être établie avec la réponse à la douleur. Ces résultats laissent penser que la diminution de la réponse au formol pourrait être en partie due aux propriétés analgésiques de la MTMZ. Le fait que la MTMZ appartienne à une classe de médicaments qui est peu explorée par rapport à la douleur et à l'analgésie indique une source potentielle pour le développement d'agents pharmacologiques nouveaux pour traiter la douleur chronique. De plus, le mécanisme d'action non opioïde laisse penser que cet agent pourrait être utile quand les opioïdes sont contre-indiqués. cer pain (2) and postoperative pain $(3,4,7)$. More recently, MTMZ has been successfully employed for the relief of cancer pain (8) and migraine headaches $(5,6)$.

The relatively small number of recent clinical reports indicates that MTMZ is infrequently used for the treatment of persistent pain. One reason may be that the agent belongs to a class of medications, phenothiazines, that is not associated with the traditional analgesics - nonsteroidal anti-inflammatory drugs and narcotics - commonly used to treat pain. However, several studies have found that some phenothiazines have apparent analgesic properties. For example, Merskey and Hester (9) reported that pericyazine provided pain relief for a patient suffering from causalgia as a consequence of a partial right median nerve lesion. At one stage during treatment the dose of pericyazine was reduced, whereupon the pain returned. When the dose of pericyazine was restored, the pain was abolished within two days. These authors noted some drowsiness with pericyazine but the effect was not significant; the patient continued with her daily routine and remained pain-free. Rodgers (8) reported the use of MTMZ in a patient sensitive to opioids who had adenocarcinoma of the right lung and possible bowel shutdown. MTMZ $10 \mathrm{mg}$ intramuscularly provided adequate relief for the patient's abdominal pain and induced mild sedation.

A second reason for the infrequent use of MTMZ may be its associated side effects. McGee and Alexander (10) argued that the analgesic properties reported by earlier studies may be attributed to MTMZ's sedative effects. Although the sedative effect has been noted by all investigators, it does not seem to present a serious deterrent to the effective use of the drug for its analgesic properties. The development of side effects associated with MTMZ, and phenothiazines in general, seems to be proportional to the total quantity taken over time (11). Some side effects, such as tardive dyskinesia, may occur even with low doses taken over several months (12). The dose required for pain relief ( 6 to $25 \mathrm{mg}$ /day) is a fraction of the dose required for antipsychotic effects (50 to $1000 \mathrm{mg}$ /day) (13). Used at levels for pain relief, MTMZ may cause side effects such as hypotension, tardive dyskinesia, delirium and dysphoria, but these are relatively rare and can be controlled by careful monitoring of the patient. Dysphoria, moreover, may be controlled with antidepressants (9).

We are aware of only one study that has examined the analgesic properties of MTMZ using an animal pain model. Maxwell et al (14) compared the analgesic properties of MTMZ with morphine in mice by measuring the number of shocks to the tail required to produce a squeak response. They found that the analgesic effect of MTMZ (indicated by a significant increase in number of shocks) was almost equal to that of morphine at lower doses. They also noted that the dose of MTMZ necessary for analgesia also produces marked sedation.
The number of effective analgesic drugs is limited, and when a trial of opioid medications fails to relieve pain it is necessary to turn to other treatment options. A recent review of adjuvant analgesics $(11,15)$ indicated that MTMZ reliably produces dose-related analgesia. Side effects are a challenge to initiate research, which may lead to new, related drugs in a class that merits further examination.

The infrequent use of MTMZ to treat persistent pain and the lack of recent animal studies have lead us to re-examine the analgesic properties of MTMZ in an animal model of tonic pain. In this report we examine the analgesic efficacy of MTMZ in a dose-related design and measure the ability of naloxone, a nonspecific opioid antagonist, to alter MTMZ-induced analgesia using the formalin test, a tonic animal pain model.

\section{ANIMALS AND METHODS}

Male Sprague-Dawley rats (Charles River Co) weighing between 275 and $300 \mathrm{~g}$ were used. Animals were housed in pairs, maintained on a $12 \mathrm{~h}$ light/12 $\mathrm{h}$ dark cycle and allowed free access to food and water. The experimental procedure was approved by the McGill University Animal Care Committee.

\section{Experiment 1}

The analgesic properties of three doses of MTMZ were assessed. Rats were randomly assigned to receive one of four drug treatments: $0.0 \mathrm{mg} / \mathrm{kg}$ MTMZ (saline control, $\mathrm{n}=10$ ); $2.5 \mathrm{mg} / \mathrm{kg}$ MTMZ ( $\mathrm{n}=10$ ); $5.0 \mathrm{mg} / \mathrm{kg}$ MTMZ ( $\mathrm{n}=10)$; or $10.0 \mathrm{mg} / \mathrm{kg}$ MTMZ ( $=10)$. The four vials containing the agents were coded before the experimental procedure to ensure that the experimenter was blind to the drug condition.

On the day of testing rats were allowed a 20 min habituation period to a $30 \times 30 \times 30 \mathrm{~cm}$ plexiglas test chamber. A mirror was placed at a $45^{\circ}$ angle underneath the floor of the chamber to facilitate viewing of the animals. Following habituation, one of the four drug doses was administered subcutaneously, followed by a $30 \mathrm{~min}$ drug absorption period. The duration of the absorption period was determined by a previous report (14) indicating that, in mice, the effect of MTMZ on the response to electrical stimulation of the tail and locomotor activity is apparent at 30 mins, and maximal at approximately $1 \mathrm{~h}$ after administration.

Each rat was administered a $0.05 \mathrm{~mL}$ injection of $2.5 \%$ formalin into the plantar surface of one hind paw. Pain responses were recorded using a pain scale of 0 to 2 . A score of 0 was assigned if the injected paw was in contact with the test floor; 1 if the injected paw was completely elevated or only the tips of the digits were in contact with the test floor; or 2 if the rat licked or bit the injected paw. The behaviour of each animal was scored continuously during the 60 mins after the formalin injection.

There is a biphasic response to formalin injection (16). The ini- 
tial phase lasts for approximately 5 mins and is followed by a diminution in responding. Second phase responses begin to increase at approximately 10 or 15 mins after formalin injection and last for an additional 40 to 70 mins. Consequently, a pain score for first phase formalin responses ( 0 to 5 mins postinjection) was calculated as ( $\mathrm{T}_{1}$ $\left.+2 \mathrm{~T}_{2}\right) / 300$, where $\mathrm{T}_{1}$ and $\mathrm{T}_{2}$ were the duration (in seconds) spent in the respective behavioural states during the $300 \mathrm{~s}(5 \mathrm{~min})$ period. The pain scores calculated during each 5 min time block from 30 to 60 mins after the formalin injection were averaged to produce a pain score for second phase formalin responses. The beginning of the 30 to $60 \mathrm{~min}$ postinjection period corresponds with the time of maximal MTMZ effect reported by Maxwell and colleagues (14).

In view of the reported sedative properties of MTMZ at doses that produce an apparent analgesic action, the animals' activity level for each dose was monitored continuously during the entire $60 \mathrm{~min}$ formalin test procedure. The floor of the test chamber was divided into four equal quadrants. A line crossing was recorded whenever both ears of a rat crossed over the boundary that defined the edge of a quadrant. This particular measure of motor behaviour allowed for the concomitant measure of sedation and formalin pain responses. The mean number of line crossings (used as an index of sedation) for each group was calculated for first phase formalin responses ( 0 to 5 mins after the formalin injection) and second phase formalin responses (30 to 60 mins postinjection).

\section{Experiment 2}

The lowest dose of MTMZ with analgesic properties in experiment $1(5.0 \mathrm{mg} / \mathrm{kg})$ was used in experiment 2 to assess whether the analgesia is due to activation of endogenous opioid systems. All rats were allowed a $20 \mathrm{~min}$ habituation period to the test chamber and then administered $5.0 \mathrm{mg} / \mathrm{kg}$ MTMZ. Ten minutes later animals were selected randomly to receive either $3.0 \mathrm{mg} / \mathrm{kg}$ naloxone $(5.0 \mathrm{mg} / \mathrm{kg}$ MTMZ and naloxone, $\mathrm{n}=10)$ or an equivalent volume of saline $(5.0 \mathrm{mg} / \mathrm{kg}$ MTMZ and saline, $\mathrm{n}=10)$. The vials containing either naloxone or saline were coded before the experimental procedure to ensure that the experimenter was blind to the drug condition. The formalin test procedure and the measure of activity level were carried out 20 mins later using the methods outlined in experiment 1. At the end of the study the vial identification codes were broken, and the identity of the test drug administered to each animal was determined.

\section{Experiment 1}

\section{RESULTS}

Mean pain scores during phase 1 responding ( 0 to 5 mins postinjection) and phase 2 responding (30 to 60 mins after formalin injection) of rats that received saline, $2.5 \mathrm{mg} / \mathrm{kg}$ MTMZ, $5.0 \mathrm{mg} / \mathrm{kg}$ MTMZ or $10 \mathrm{mg} / \mathrm{kg}$ MTMZ are illustrated in Figure 1A. Nonparametric analysis (Kruskall-Wallace) on first phase responding revealed no significant mean pain score differences among the groups $(\mathrm{H}=6.17$, $\mathrm{P}>0.05$ ). Nonparametric analysis (Kruskall-Wallace) on second phase responding revealed a significant difference of mean pain scores among the groups $(\mathrm{H}=12.55, \mathrm{P}<0.01)$. Further analysis (MannWhitney $U$ test) indicated that both the $5.0 \mathrm{mg} / \mathrm{kg}$ MTMZ and $10.0 \mathrm{mg} / \mathrm{kg}$ MTMZ groups had lower mean pain scores compared with both the saline and $2.5 \mathrm{mg} / \mathrm{kg}$ MTMZ groups. The $2.5 \mathrm{mg} / \mathrm{kg}$

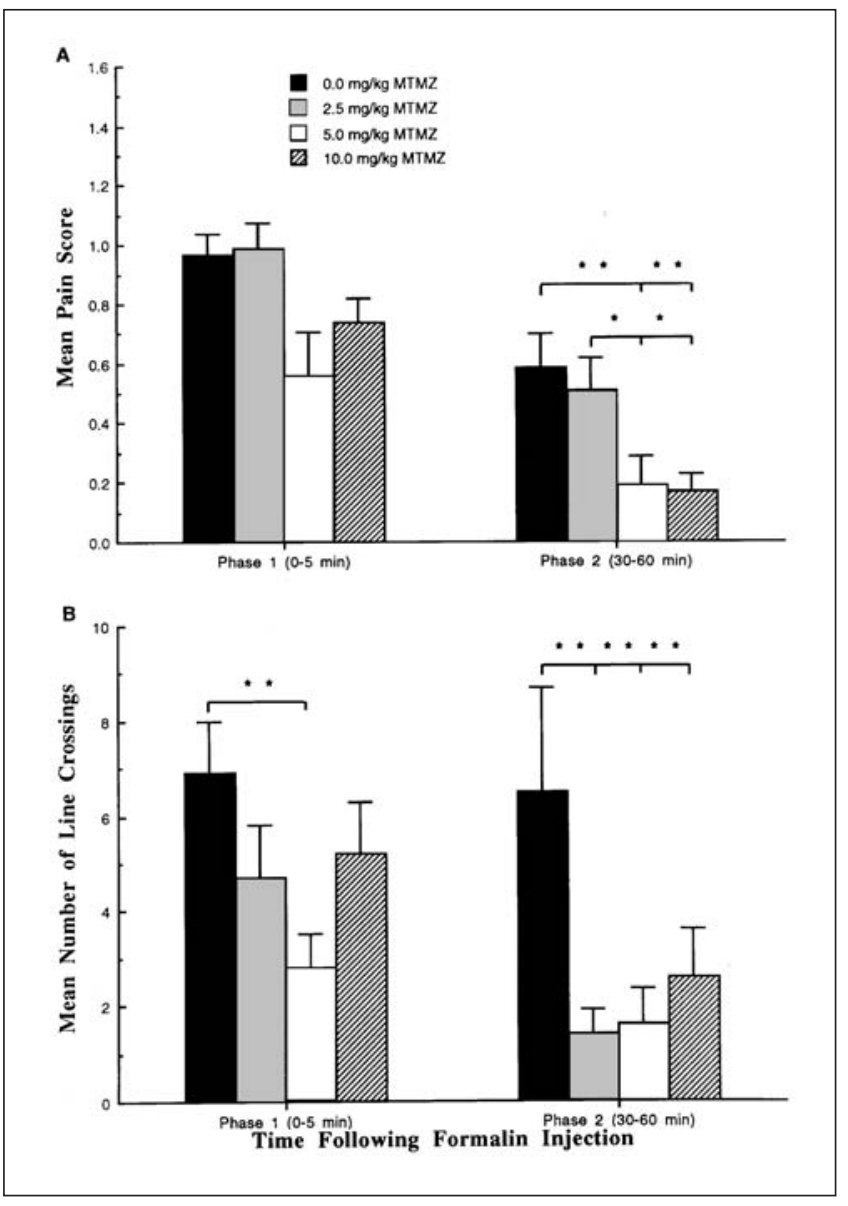

Figure 1) A Mean formalin pain scores of rats receiving $0.0 \mathrm{mg} / \mathrm{kg}$ methotrimeprazine (MTMZ) (saline control, $n=10) ; 2.5 \mathrm{mg} / \mathrm{kg} \mathrm{MTMZ}(\mathrm{n}=10)$; $5.0 \mathrm{mg} / \mathrm{kg} \mathrm{MTMZ}(\mathrm{n}=10)$; or $10.0 \mathrm{mg} / \mathrm{kg} \mathrm{MTMZ}(\mathrm{n}=10)$. B Mean number of line crossings (a measure of sedation) during first phase and second phase formalin responses. ${ }^{*} \mathrm{P}<0.05 ;{ }^{*} \mathrm{P}<0.01$

MTMZ group was not significantly different from the saline control group.

Sedation effects were studied by using the line crossing test concomitantly with the formalin test. The mean number of line crossings during phase 1 responding ( 0 to 5 mins after the formalin injection) and phase 2 responding (30 to 60 mins postinjection) is illustrated in Figure 1B. Parametric analysis (ANOVA) revealed a significant difference among the groups during phase 1 responding $(\mathrm{F} 3,36=2.96, \mathrm{P}<0.05)$. Further analysis (protected $t$ test) indicated that the $5.0 \mathrm{mg} / \mathrm{kg}$ MTMZ group made significantly fewer line crossings than the saline control group. Parametric analysis (ANOVA) during phase 2 responding also revealed a significant difference among the groups $(\mathrm{F} 3,36=3.52, \mathrm{P}<0.05)$. Further analysis (protected $t$ test) indicated that the $2.5 \mathrm{mg} / \mathrm{kg} \mathrm{MTMZ,} 5.0 \mathrm{mg} / \mathrm{kg}$ MTMZ and $10.0 \mathrm{mg} / \mathrm{kg}$ MTMZ groups had significantly fewer line crossings compared with controls.

If sedative effects account for the apparent analgesic properties of MTMZ, then a positive relationship may exist between increased degree of sedation and increased degree of analgesia. Overall analysis (Spearman correlation coefficient) during the second phase, using all animals that received MTMZ, revealed no significant relationship between number of line crossings and mean pain score 

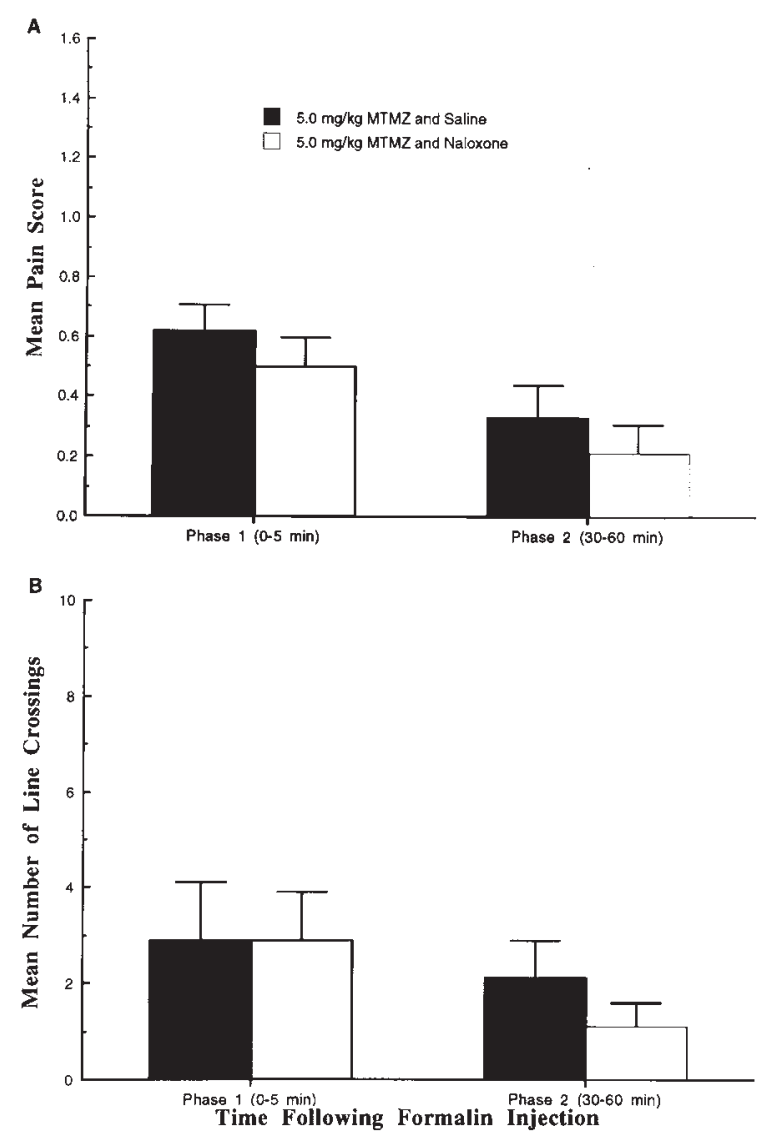

Figure 2) A Mean formalin pain responses for the group that received $5.0 \mathrm{mg} / \mathrm{kg}$ methotrimeprazine (MTMZ) and naloxone $(\mathrm{n}=10)$ or $5.0 \mathrm{mg} /$ kg MTMZ and saline $(n=10)$. B Mean number of line crossings during first phase and second phase formalin responses

$(\mathrm{r}=-0.04, \mathrm{P}>0.80)$. The lack of relationship most likely reflects the group data, demonstrating that decreased mean pain scores are associated with increased number of line crossings (Figure 1). Consequently, the relationship between mean pain score and number of line crossings was explored for each dose of MTMZ from 30 to 60 mins after the formalin injection. Analysis (Spearman correlation coefficient) revealed no significant relationship between number of line crossings and mean pain score at any dose of MTMZ. Therefore, although higher doses of MTMZ produce both sedative and analgesic effects (Figure 1), there is no indication that increased degree of sedation is correlated with increased degree of analgesia.

\section{Experiment 2}

Mean pain scores during phase 1 responding ( 0 to 5 mins after the formalin injection) and phase 2 responding (30 to 60 mins postinjection) of rats that received MTMZ and either naloxone $(5.0 \mathrm{mg} /$ $\mathrm{kg}$ MTMZ and naloxone) or saline (5.0 mg/kg MTMZ and saline) are illustrated in Figure 2A. Nonparametric analysis (MannWhitney $U$ test) revealed no significant group differences during either first or second phase formalin responding.

The mean number of line crossings during phase 1 responding $(0$ to 5 mins after the formalin injection) and phase 2 responding (30 to
60 mins postinjection) is illustrated in Figure 2B. Parametric analysis (ANOVA) revealed no significant group difference during either first phase or second phase formalin responding.

\section{DISCUSSION}

The purpose of this study was to investigate the analgesic properties of MTMZ in a dose-related design and to determine whether the analgesia is due to activation of endogenous opioid systems. Although MTMZ failed to produce a significant decrease during first phase formalin responses, there was a significant decrease in second phase formalin responses for both the $5.0 \mathrm{mg} / \mathrm{kg}$ and $10.0 \mathrm{mg} / \mathrm{kg}$ MTMZ doses, but not for the $2.5 \mathrm{mg} / \mathrm{kg}$ MTMZ dose. This study supports results from earlier studies that found analgesic properties of MTMZ in mice using a phasic pain test (14) and clinical studies reporting MTMZ to be effective for the treatment of various types of pain (1-8).

The analgesic properties attributed to MTMZ may be the result of sedative effects (10). Indeed, clinical studies have reported that the average level of sedation is much greater with MTMZ than with morphine $(1,2,4,7)$. The sedative effects of chronic MTMZ treatment for cancer pain are unpredictable (2). Some patients tolerated repeated administration of the drug while others reported significant and long-lasting sedation after a single administration. Patients may overcome the sedative effect after a few days, and the dose may be increased to provide better analgesia (8).

The sedative effects associated with MTMZ were also found in the present study. It is possible that the decrease of formalin responses obtained at higher doses is not due to analgesic properties of the drug, but rather reflects the drug's general sedative properties. However, several forms of evidence suggest that although MTMZ possesses significant sedative effects, it may also possess intrinsic analgesic properties. For example, during first phase responding the $5.0 \mathrm{mg} / \mathrm{kg}$ MTMZ group made significantly fewer line crossings (indicating increased sedation) compared with controls (Figure 1B) even though there was no significant associated decrease in first phase pain responding between these groups (Figure 1A). During second phase responding, the formalin responses of the saline control and $2.5 \mathrm{mg} / \mathrm{kg}$ MTMZ groups did not differ (Figure 1A) even though $2.5 \mathrm{mg} / \mathrm{kg}$ MTMZ produced a significantly greater sedative effect (Figure 1B). It should also be noted that the $5.0 \mathrm{mg} / \mathrm{kg}$ MTMZ and $10.0 \mathrm{mg} / \mathrm{kg}$ MTMZ groups had lower formalin responses compared with the $2.5 \mathrm{mg} / \mathrm{kg} \mathrm{MTMZ}$ group (Figure 1A), but there was no difference among these groups in the number of line crossings (Figure 1B). In addition, statistical analysis revealed that there was no significant correlation between degree of sedation and analgesia at any dose of MTMZ. At any particular dose, increased degree of sedation did not correlate with increased analgesic effect. However, the interpretation of the lack of such a correlation must be made with caution since the sedative effects seem to reach a maximum at a dose of $2.5 \mathrm{mg} / \mathrm{kg}$, which is below the dose producing analgesia.

We believe that the results suggest that MTMZ has analgesic properties in addition to its obvious sedative effects. This conclusion is supported by clinical reports of tolerance to the sedative effect without a concomitant decrease in the efficacy of the analgesic effect (8), further indicating that the analgesic properties of MTMZ are not produced by its sedative properties. However, the results are not conclusive and further research is needed, particularly with hu- 
mans, to provide subjective reports that will allow discrimination between the two effects. Use of the McGill Pain Questionnaire together with a battery of tests of cognitive alertness will provide indexes of the relative effects of MTMZ on analgesia and sedation. The sedative effects associated with the doses of MTMZ required for analgesic effects warrant caution for further research using animal models, and research may examine the possibility that repeated administration of MTMZ may overcome the sedative properties of the agent.

The underlying mechanism associated with the analgesic properties of MTMZ remains unknown. However, the lack of an effect by a relatively large dose of naloxone $(3 \mathrm{mg} / \mathrm{kg}$ ) indicates that the analgesia produced by $5.0 \mathrm{mg} / \mathrm{kg}$ MTMZ is nonopioid-mediated. Although this result is not surprising, given the possible involvement of dopaminergic action for the drugs's antipsychotic effect (17), we deemed it important to eliminate an opioid mechanism of action because of the important clinical implications. The nonopioid mechanism of action makes this agent potentially useful for pain relief in patients who are unresponsive to more conventional pharmacological approaches, or when opioid medications are contraindicated due to a previous history of substance abuse and severe negative reactions to opioid medications. Future research concerning possible mechanisms of action should concentrate on the possi-

\section{REFERENCES}

1. Montilla E, Fredrick WS, Cass LJ. Analgesic effect of methotrimeprazine and morphine. Arch Intern Med 1963;111:725-8.

2. Beaver WT, Wallenstein MS, Houde RW, Rodgers A. A comparison of the analgesic effects of methotrimeprazine and morphine in patients with cancer. Clin Pharmacol Ther 1966;7:436-46.

3. Fazio AN. Control of postoperative pain: a comparison of the efficacy and safety of pentazocine, methotrimeprazine, meperidine and a placebo. Curr Ther Res 1970;12:73-7.

4. Taylor RG, Doku HC. Methotrimeprazine: evaluated as an analgesic following oral surgery. J Oral Med 1967;22:141-4.

5. Hoag R, Mortimer L. Methotrimeprazine compared to meperidine and dimenhydrinate in the treatment of migraine heachache. CAEP Review 1989;7:29-31.

6. Stiell IG, Dufour DG, Moher D, Yen M, Beilby WJ, Smith NA. Methotrimeprazine versus meperidine and dimenhydrinate in the treatment of severe migraine: a randomized, controlled trial. Ann Emerg Med 1991;20:1201-5.

7. Lasagna L, De Kornfeld TJ. Methotrimeprazine: a new phenothiazine derivative with analgesic properties. JAMA 1961;178:887-90.

8. Rodgers AG. The use of methotrimeprazine (levoprome) in a patient sensitive to opioids and possible bowel shutdown. J Pain Symptom Manage 1989;4:44-5.

9. Merskey H, Hester RN. The treatment of chronic pain with psychotropic drugs. Postgrad Med J 1972;48:594-8.

10. McGee JL, Alexander MR. Phenothiazine analgesia - fact or fantasy. Am J Hosp Pharm 1979;36:633-40. ble involvement of dopaminergic and noradrenergic systems using the appropriate antagonists.

\section{CONCLUSIONS}

MTMZ is a phenothiazine derivative not commonly employed as a pharmacological agent to treat chronic pain. The present experiment demonstrates that, although MTMZ elicits significant sedative effects, it can produce a dose-dependent analgesia using a tonic animal pain model. These findings have significant clinical implications since few drugs have the analgesic potency of the opioids and the potential to treat persistent pain $(11,15)$. The fact that MTMZ is a nonopioid and belongs to a class of drugs that is relatively unexplored in relation to pain and analgesia, indicates that it may provide information for the development of new pharmacological agents for treating persistent pain. MTMZ has apparent analgesic properties and merits further research. The present study shows that the formalin test provides an effective animal model.

ACKNOWLEDGEMENTS: This study was supported by a Natural Science and Engineering Research Council of Canada Grant (A7891) to Dr Melzack. Dr Fuchs was supported in part by a grant from the Montreal General Hospital Pain Center.

11. Monks R. Psychotropic Drugs. In: Wall PD, Melzack R, eds. Textbook of Pain, 3rd edn. Edinburgh: Churchill Livingstone, 1994:963-89.

12. Monks RC. Tardive dyskinesia with low dose neuroleptic therapy. Mod Med 1980;35:519.

13. Canadian Pharmaceutical Association. Compendium of Pharmaceuticals and Specialties, 30th edn. Toronto: Southam Murray, 1995.

14. Maxwell DR, Palmer HT, Ryall RW. A comparison of the analgesic and some other central properties of methotrimeprazine and morphine. Arch Int Pharmacodyn Ther 1961;130:60-73.

15. Patt RB, Proper G, Reddy S. The neuroleptics as adjuvant analgesics. J Pain Symptom Manage 1994;9:446-53.

16. Dubuisson S, Dennis SG. The formalin test: a quantitative study of the analgesic effects of morphine, meperidine, and brain stem stimulation in rats and cats. Pain 1977;4:161-74.

17. Baldessarini RJ. Drugs and the treatment of psychiatric disorders. In: Gilman AG, Rall TW, Nies AS, Taylor P, eds. The Pharmacological Basis of Therapeutics, 8th edn. New York: Pergamon Press, 1990:383-435. 


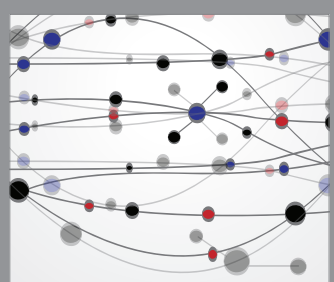

The Scientific World Journal
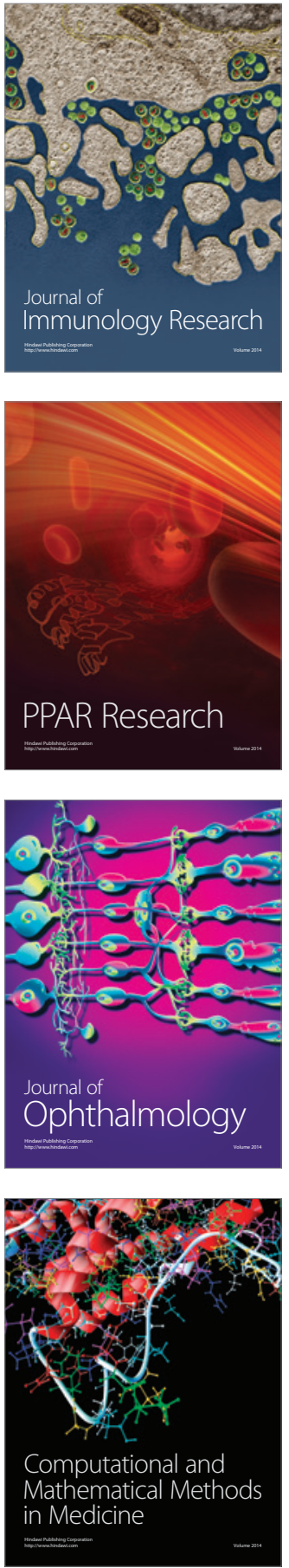

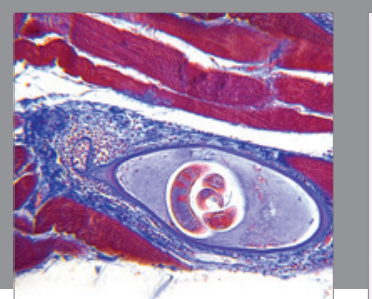

Gastroenterology Research and Practice

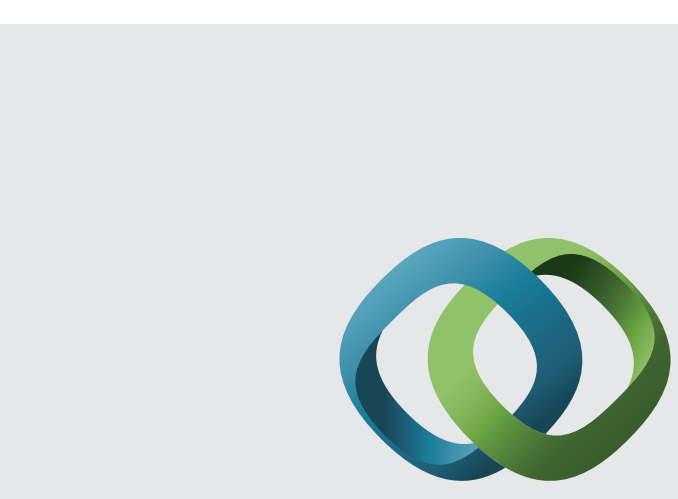

\section{Hindawi}

Submit your manuscripts at

http://www.hindawi.com
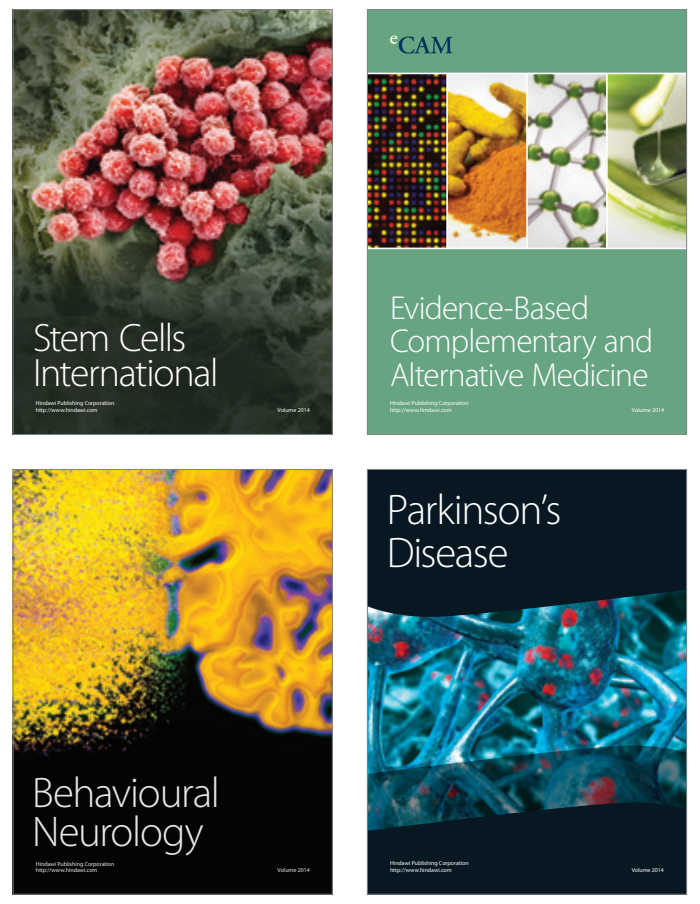
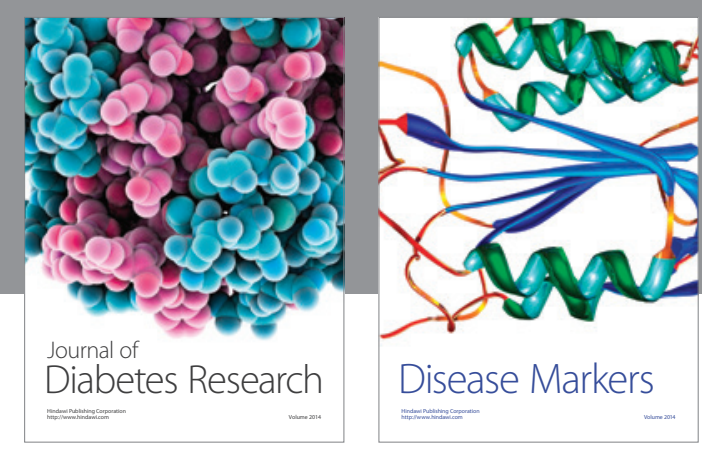

Disease Markers
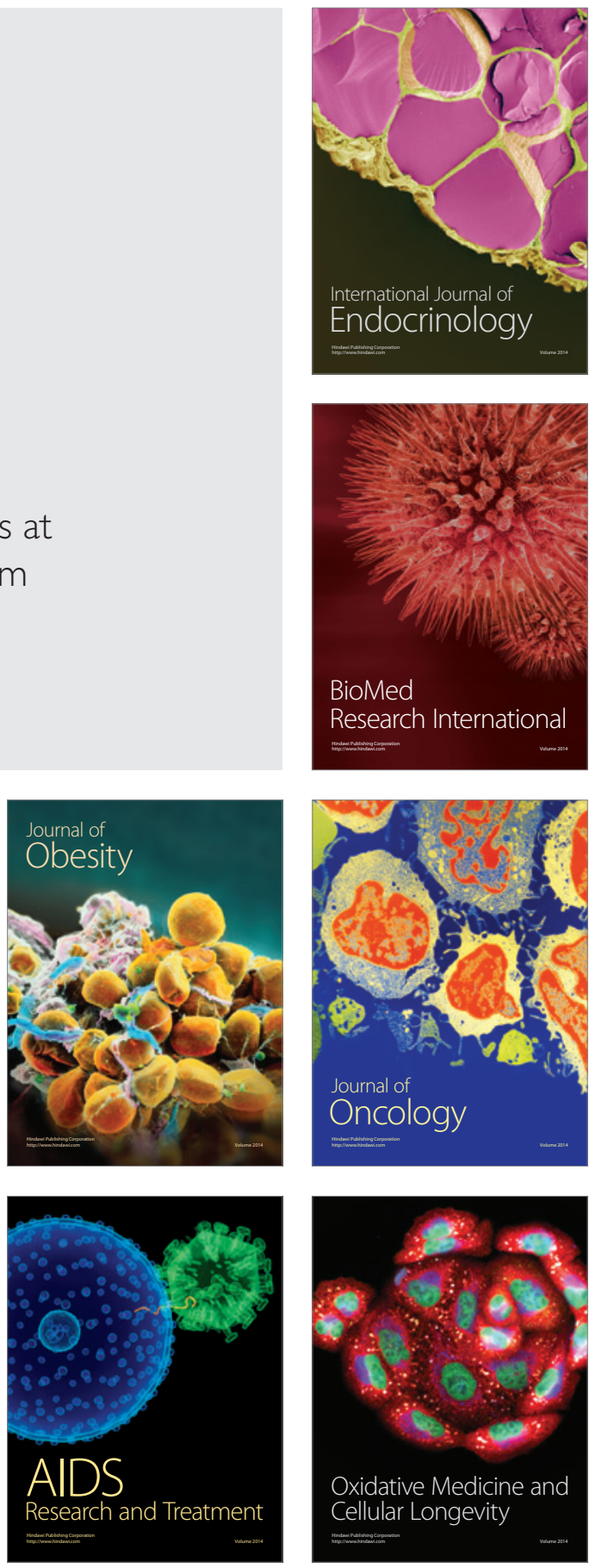